\title{
Condom ileus: result of a practical joke
}

\author{
W.G.A. Woods* \\ Central Middlesex Hospital, London NW 10, UK.
}

\begin{abstract}
Summary: Ingestion of toy balloons and condoms filled with drugs is well recognized. A case is reported in which a fluid filled condom ingested as a result of a practical joke caused intestinal obstruction.
\end{abstract}

\section{Introduction}

There have been several reports of condom or toy balloon ingestion and their complications. These have all been related to attempts to use these devices as a means of smuggling morphine, ${ }^{1}$ cocaine, ${ }^{2}$ or marihuana. ${ }^{3}$ This is the first report of a case in which a fluid filled condom, swallowed as a result of a practical joke, caused intestinal obstruction.

\section{Case report}

A 19 year old male was admitted to the Central Middlesex Hospital, London, with a 72 hour history of colicky abdominal pain, abdominal distension, vomiting, and absolute constipation. Twelve hours before the onset of the pain he had taken part in a beer drinking competition during the course of which he had the sensation of swallowing something which felt like a marble. He had had an appendicectomy 11 years previously.

Physical examination revealed the signs of intestinal obstruction. The scar of the previous appendicectomy was noted. Erect and supine abdominal X-rays showed fluid levels and distended loops of small bowel, but no foreign body.

A diagnosis of adhesion obstruction was made, and he was treated conservatively with intravenous fluid replacement and nasogastric aspiration. Despite an initial temporary improvement, after 24 hours the obstruction had not resolved. X-rays now revealed a circular opacity in the pelvis.

At laparotomy the small bowel was found to be distended to a point $50 \mathrm{~cm}$ from the ileo-caecal valve. At this site a Meckel's diverticulum was found with an associated congenital band partly obstructing the lumen of the adjacent ileum. Two soft, roughly

Correspondence: W.G.A. Woods M.A., F.R.C.S., 47, Scarsdale Villas, London W8 6PU, UK.

*Present address: The London Hospital, London E1 1BB.

Accepted: 16 December 1986 spherical, intraluminal, foreign bodies about $4 \mathrm{~cm}$ in diameter were palpable just proximal to this. These were removed through an enterotomy and proved to be fluid filled condoms (Figure 1). The enterotomy was closed and the band divided. The patient made an uneventful postoperative recovery.

\section{Discussion}

Previous reports of the complications of condom or toy balloon ingestion have related to their use for smuggling morphine, ${ }^{1}$ cocaine, ${ }^{2}$ or marihuana. ${ }^{3}$ The

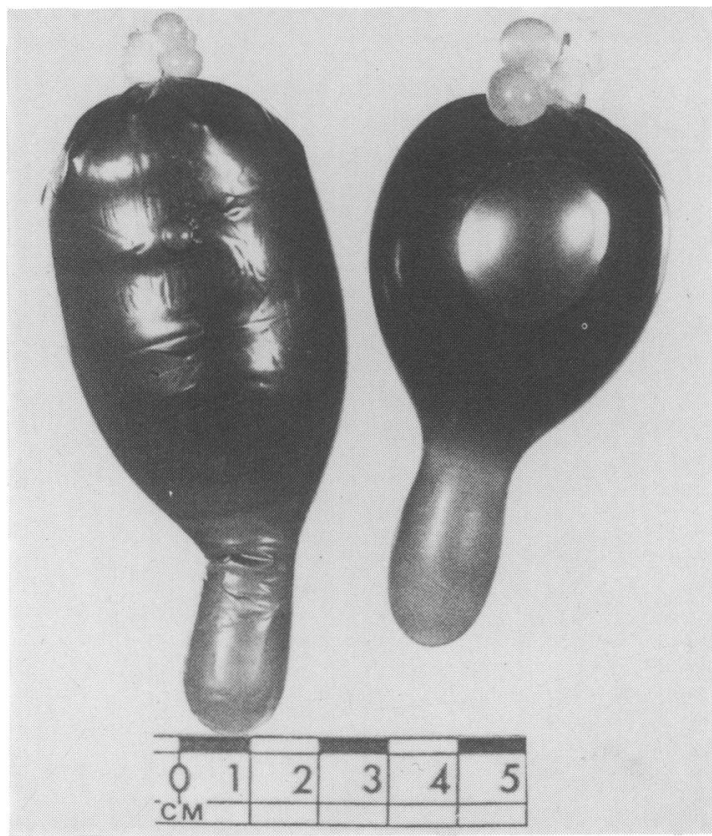

Figure 1 Fluid filled condoms recovered from the small bowel. 
most serious complication in these circumstances is rupture of the condom or balloon with release of its contents. The resulting narcotic overdose is frequently fatal. ${ }^{4}$ In these cases removal of the condoms from the gastrointestinal tract is strongly advised before rupture has taken place.

Intestinal obstruction has been reported following condom or toy balloon ingestion, but only in special circumstances. In one report ${ }^{3}$ the condoms were held up in the stomach because of pyloric stenosis. Dassel \& Punjabi $^{5}$ report obstruction occurring in three unrelated circumstances: (a) multiple condoms becoming entangled and forming a bolus too large to pass further through the small bowel; (b) fermentation producing gaseous distension in the condom; and (c) adhesions narrowing the bowel lumen and preventing onward movement of the condoms, as happened in the present case.

This is the first report of a case in which a fluid filled

\section{References}

1. Pinsky, M.F., Ducas, J. \& Ruggere, M.D. Narcotic smuggling: the double condom sign. J Can Assoc Radiol 1978, 29: 79-81.

2. Freed, T.A., Sweet, L.N. \& Gauder, P.J. Balloon obturation small bowel obstruction: a hazard of drug smuggling. Am J Roentgenol 1976, 127: 1033-1034.

3. Doran, J. \& Amar, S.S. An unusual case of "pot belly". Br Med J 1977, 2: 1630. condom was swallowed as the result of a practical joke, and the additional hazard of rupture and massive drug release was therefore not present. Review of previous publications indicates that under most circumstances ingested condoms or balloons will be passed spontaneously. These patients should, therefore, be managed expectantly unless the contents of the condom would be dangerous if released into the intestine as a result of rupture. Persistence of the signs and symptoms of intestinal obstruction for more than 24 hours suggests that there is some other factor present and that laparotomy will be required.

\section{Acknowledgement}

I would like to thank Mr J.F. Newcombe, M.Chir., F.R.C.S. for his advice, and for permission to report this case which came under his care.

4. Suarez, C.A., Aranhgo, A. \& Lester, J.L. Cocaine condom ingestion. Surgical treatment. JAMA 1977, 238: 1391-1392.

5. Dassel, P.M. \& Punjabi, E. Ingested marihuana filled balloons. Gastroenterology 1979, 76: 166-169. 